\title{
Em Edimburgo (Inglaterra?) mas com o coração em Damasco (lraque?)
}

\author{
Rui Pina Coelho
}

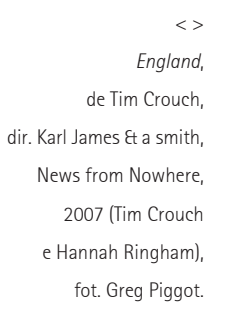

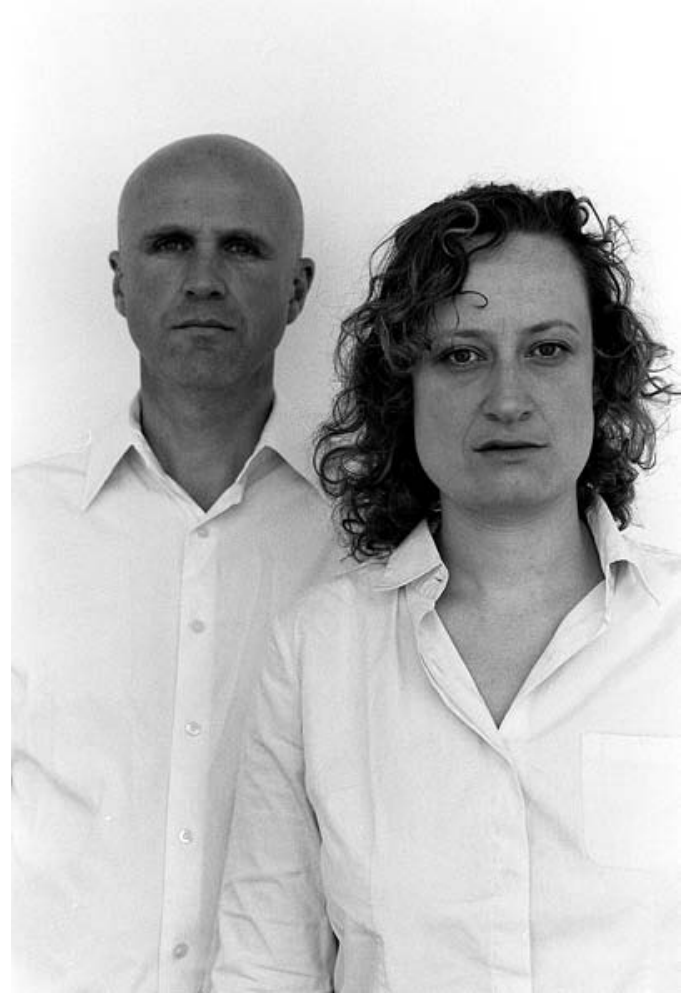

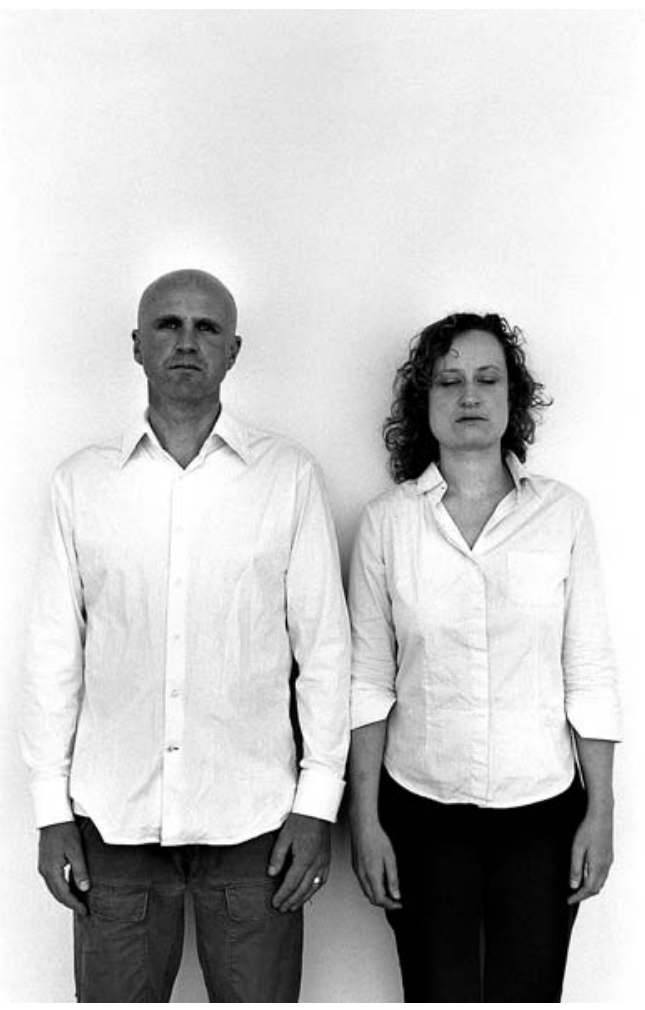

Titulo: England (2007). Autor: Tim Crouch. Encenação: Karl James \&t a smith. Desenho de som: Dan Jones. Interpretação: Tim Crouch e Hannah Ringham. Produção: news from nowhere / The Traverse Theatre / The Fruitmarket Gallery. Local e data de estreia: The Fruitmarket Gallery, Edimburgo, 4 de Agosto de 2007.

Título: Damascus (2007). Autor: David Greig. Encenação: Philip Howard. Cenografia: Anthony Macllwaine. Desenho de Luz: Chahine Yavroyan. Música: Jon Beales. Desenho de som: Graham Sutherland. Treino de dialectos: Ros Steen. Assistência de encenação: David Overend. Interpretação: Dolya Gavanski, Paul Higgings, Khalid Armin e Alex Elliott. Produção: Traverse Theatre Company. Local e data de estreia: Traverse Theatre, Edimburgo, 27 de Julho de 2007.

Ver teatro em Edimburgo no mês de Agosto é muito difícil. Escolher um espectáculo de entre a abundante oferta que os vários festivais da cidade oferecem pode revelar-se uma tarefa extremamente complicada. Será fácil eliminar logo à partida todos os eventos que os vários festivais de cinema, de literatura, de artes plásticas ou de música oferecem? Ou ignorar o espectáculo em que a própria cidade se transforma? E depois, será fácil seleccionar de entre a exigente programação do Edinburgh International Festival' ou acompanhar a ecléctica mesclagem de artes performativas que o Fringe propõe? Só para esta última edição do festival - o off mais emblemático de todos - a programação oficial ocupava um extenso caderno de 288 (!) páginas.
No meio deste circo de espectáculos onde todos querem distribuir o panfleto mais apelativo ou ter o cartaz mais bizarro; onde os actores exibem os momentos mais intensos dos seus espectáculos na movimentada Royal Mile lutando por cada metro quadrado com stand up comediants, malabaristas, cuspidores de fogo, cantoras líricas em cima de amplificadores e com todo um exército de artistas de rua; no meio de toda esta ruidosa programação de espectáculos apresentados na rua ou dentro de carros, de teatro do gesto ou da palavra, em inglês ou em búlgaro; onde se trituram os clássicos e se apresentam as promessas; onde o desejo de sobressair é tal que cada espectáculo quase que propõe um novo 


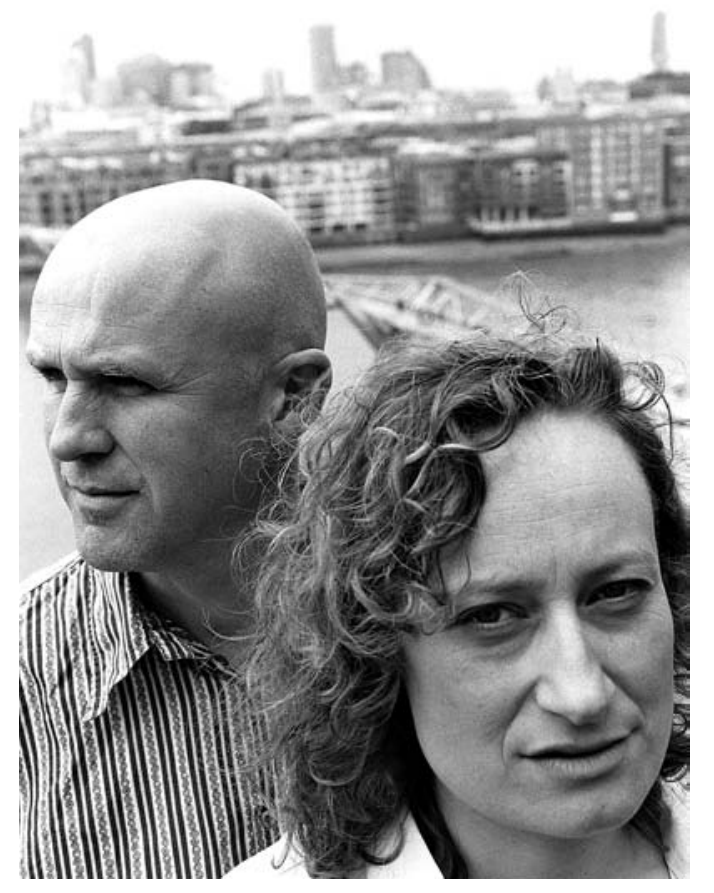

sub-género; no meio de toda esta confusão pode ser dificil escutar a serena novidade que o último espectáculo de Tim Crouch aporta ${ }^{2}$.

England é um espectáculo para ser apresentado em galerias de arte. Com texto de Crouch, é dirigido por Karl James e por a smith [sic], é interpretado pelo próprio autor e por Hannah Ringham, e é apresentado pela News From Nowhere, uma estrutura de produção sediada em Brighton (Inglaterra) com o objectivo de produzir o trabalho de Crouch e de "explorar as fronteiras entre o teatro, a educação e as artes visuais" ${ }^{3}$ - é co-produzido pela The Traverse Theatre Company, pela Fruitmarket Gallery, pelo Warwick Arts Centre e pela portuguesa Culturgest.

Em Edimburgo, England é apresentado na Fruitmarket Gallery onde está patente uma exposição / instalação do artista britânico Alex Hartley (n. 1963). Apesar de ser circunstancial (noutras localidades será apresentado com outros trabalhos), não deixa de ser significativo que a exposição de Hartley mostre várias fotografias do artista a escalar edifícios urbanos (buildering) onde o elemento humano aparece como que a parasitar a superficie arquitectónica. Com efeito, também o trabalho de Crouch explora esta ideia de um corpo que habita um objecto estranho, transposto para fora do seu contexto. Dividido em duas partes, na primeira assistimos à breve história de uma personagem, namorado/a de um vendedor de arte que, devido a problemas cardíacos, tem que receber um transplante de coração. Na segunda parte, esta personagem procura a viúva do dador do seu coração, um árabe, para lhe agradecer. De acordo com o programa do espectáculo: "Esta é a história de uma coisa dentro de outra: um coração dentro do corpo de uma outra pessoa, uma cultura dentro da cultura de um outro pais, um teatro dentro de uma galeria, uma personagem dentro de um actor, uma peça dentro do seu público". Com efeito, a ideia de transplante aparece como estruturante a um texto que viaja por um elenco de temas tão vasto como o comércio de arte, a globalização dos olhares, a solidão urbana, a economia dos afectos, a arte como terapia para a doença..., numa linguagem plena de poesia e de refrães, que colocam o espectador sempre em atenção e na necessidade de encontrar o referente correcto. 


\section{$>$
Damascus,
de David Greig,
dir. Philip Howard,
Traverse Theatre
Company, 2007
(Dolya Gavanski
e Paul Higgins),} fot. Alan McCreedie.

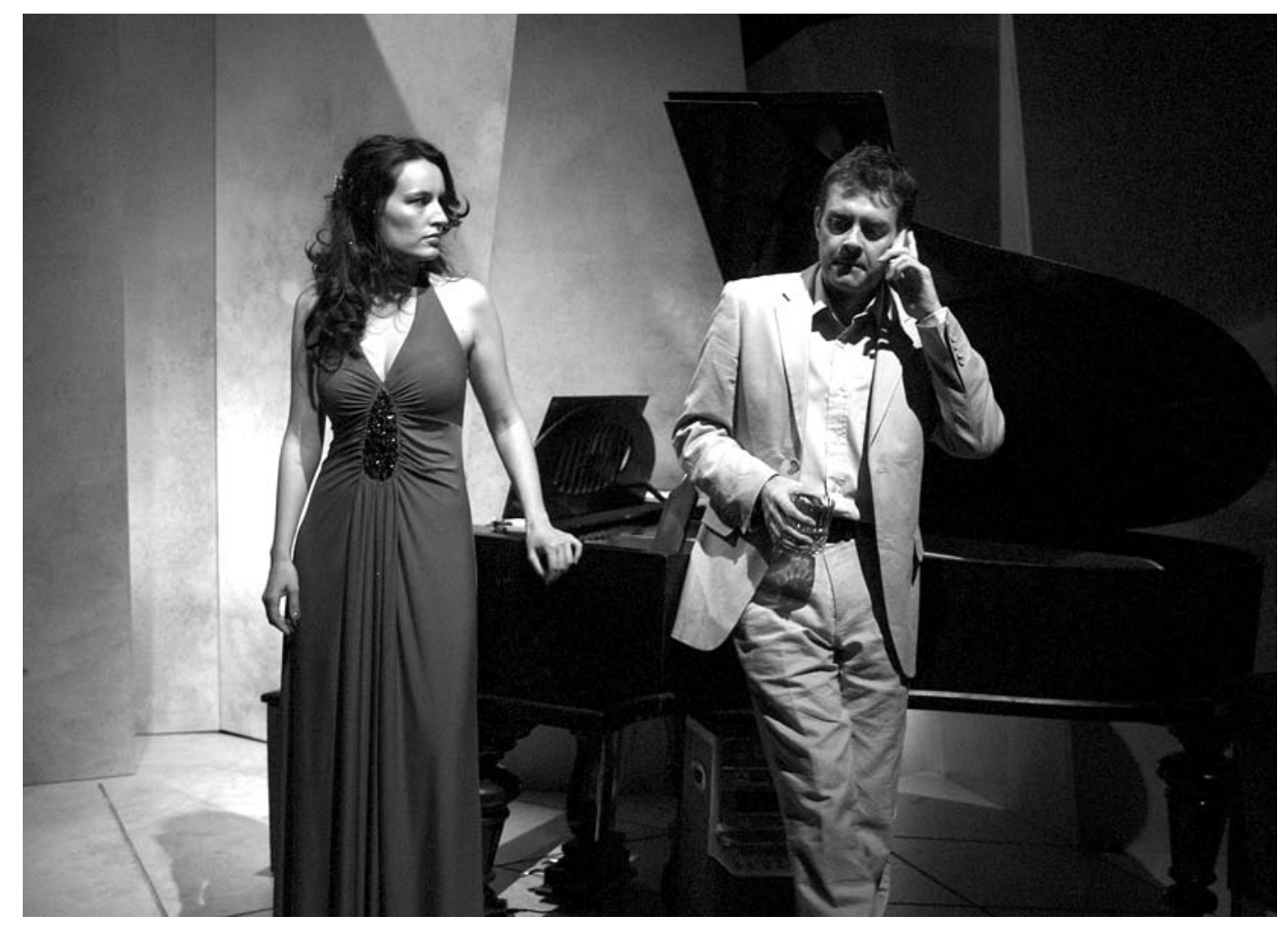

Assim, por exemplo, "Salvaste-me a vida" tanto vai significando um agradecimento ao público - por estar a assistir -, ao Scottish Arts Council - por converter o antigo mercado numa galeria de arte -, ao namorado - pelo amor - , à arte - pela ajuda na doença - , ao médico - pelo diagnóstico - ou, finalmente à viúva do dador - pelo coração. Mas, porventura, o mais explícito refrão será o imperativo "Olha!" que vai colocando o público na estimulante situação de olhar para as fotografias de Alex Hartley ou de descobrir nas linhas brancas e frias da galeria as mesmas linhas de um apartamento requintado em Londres, de uma igreja ou de um quarto de hospital.

Apesar do aparato conceptual com que se mascara o espectáculo, a simplicidade com que se apresenta é desarmante. A narrativa é contada por dois guias que supostamente ali estão para mostrar a exposição de arte, mas que vão progressivamente perdendo esta função e assumindo-se na primeira pessoa do singular, adoptando a dimensão de vozes, uma masculina, outra feminina. Apesar da diferença de género são ambos a mesma personagem (o homem / a mulher que recebe um transplante) o que coloca a sua figuração ao mesmo nível que o entendimento do espaço onde decorre a acção: ou seja, fica ao critério da imaginação do espectador, o que nos deixa muito próximos de um estado de pureza teatral.

Sendo que em cada representação os dois intérpretes negociarão ao vivo o que cada um dirá, assiste-se a um jogo de repetições, sobreposições, arritmias e silêncios que dá ao espectáculo uma intensidade e vibração muito peculiares. Para tal contribuirá também a rapidez com que as vozes passam de personagens a desabafos líricos. Assim, apesar do carácter estático da proposta cénica (dois actores que contam uma história parados junto a uma fotografia, numa galeria de arte) o que nos é proposto é uma vertiginosa viagem mental.

Crouch e Ringham, de roupas casuais e quotidianas, representam com visivel prazer, escondendo (ou provocando) com sorrisos inocentes um desequilibrio que oscila entre o desconforto de representar e o prazer pueril de contar uma história a quem a quer ouvir.

Se na primeira parte do espectáculo os dois actores 


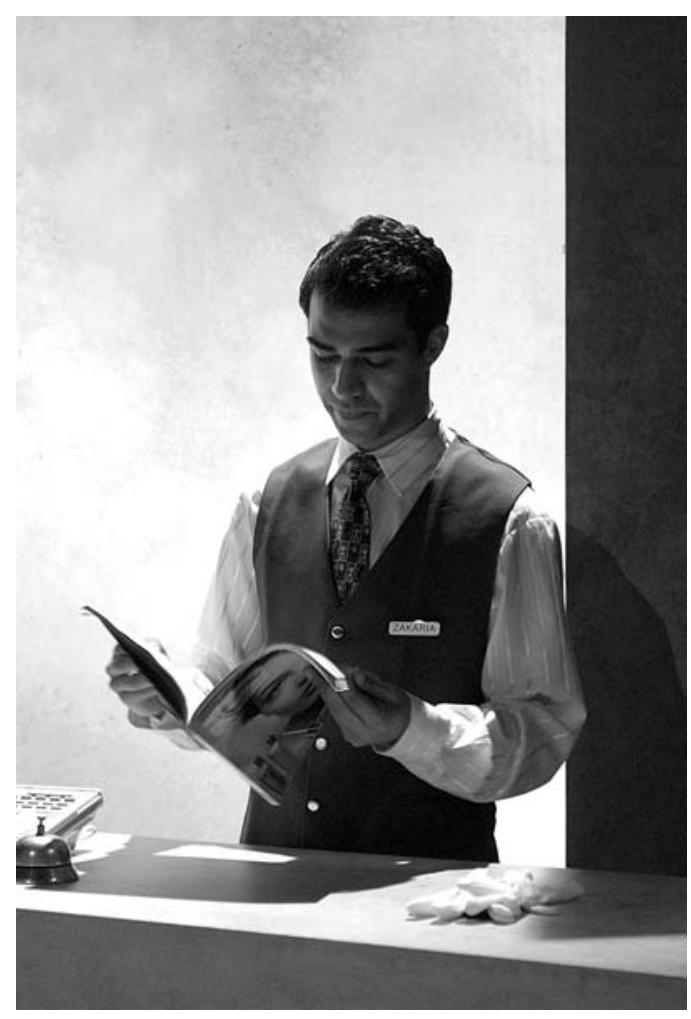

estão rodeados pelos espectadores e próximos das obras de arte, na segunda todo o aparato é mais convencional: numa outra sala da galeria, com os espectadores já sentados, o duo de actores (um o Inglês, o outro o Intérprete), lado a lado, dirigem-se à viúva do dador do coração (o público...) para Ihe agradecer. Com a acção situada agora algures no Médio Oriente, a inocência do gesto de agradecimento é confrontada com problemas de linguagem, diferenças de classe e de etnia, numa história onde o comércio de órgãos se confunde com o comércio de obras de arte. Os refrães voltam a ouvir-se ("Obrigado", "Salvaste-me a vida", "Olha!"), mas agora com uma literalidade que torna tudo mais brutal e muito mais incómodo.

Depois da saida dos actores, só no final, nos damos conta que o desconforto com que ficamos (nós, europeus) já antes tinha sido anunciado no título, England. A escolha por um topónimo faz radicar a questão na origem do olhar e no facto de que a nossa compreensão do mundo está inexoravelmente ligada ao sítio de onde olhamos, impondo os limites da nossa imaginação.

Tal parece ser também a premissa de David Greig,

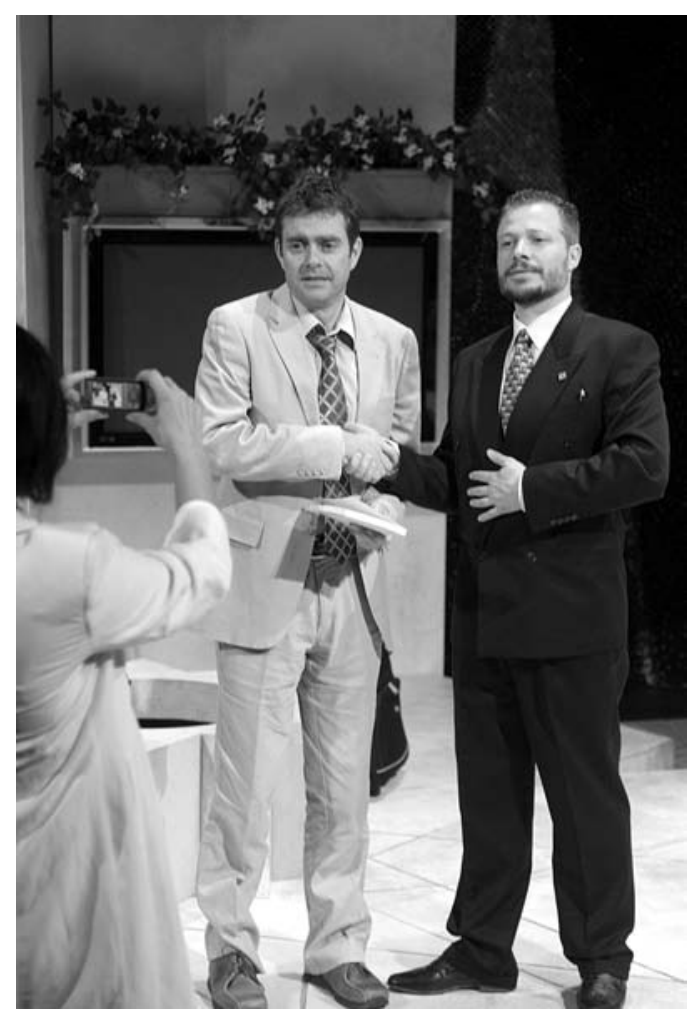

$<>$

Damascus,

de David Greig,

dir. Philip Howard,

Traverse Theatre

Company, 2007

(< Khalid Laith;

$>$ Nathalie Armin,

Paul Higgins e Alex Elliot),

fot. Alan McCreedie. com um texto que também tem por título um topónimo: Damascus. Aqui, acompanhamos a história de Paul (Paul Higgins), um autor e vendedor de manuais de língua inglesa, que viaja - relutantemente, pois deixa a sua mulher no Dia dos Namorados - para Damasco, com o objectivo de fechar um negócio. Contudo, e se as coisas não correm muito bem do ponto de vista comercial - com uma estadia que se supunha curta a tornar-se cada vez mais prolongada - do ponto de vista afectivo, Paul vai descobrindo cada vez mais motivos de interesse na capital da Síria: a bela Muna (Nathalie Armin), a sua interlocutora comercial, vai estimulando nele um interesse amoroso ao mesmo tempo que o vai instruindo no verdadeiro sentido da multiculturalidade; e Zacharia (Khalid Laith), o cómico recepcionista do hotel em que está albergado, vai alimentando nele uma simpatia paternal e vai entretendo os seus tempos mortos com discotecas e sonhos de um dia chegar a Hollywood. Haverá ainda Wasim (Alex Elliot), reitor de um colégio e potencial comprador dos manuais, mas que já se desinteressou do negócio e que disputa agora com Paul os afectos de Muna. Ao fundo, Elena 


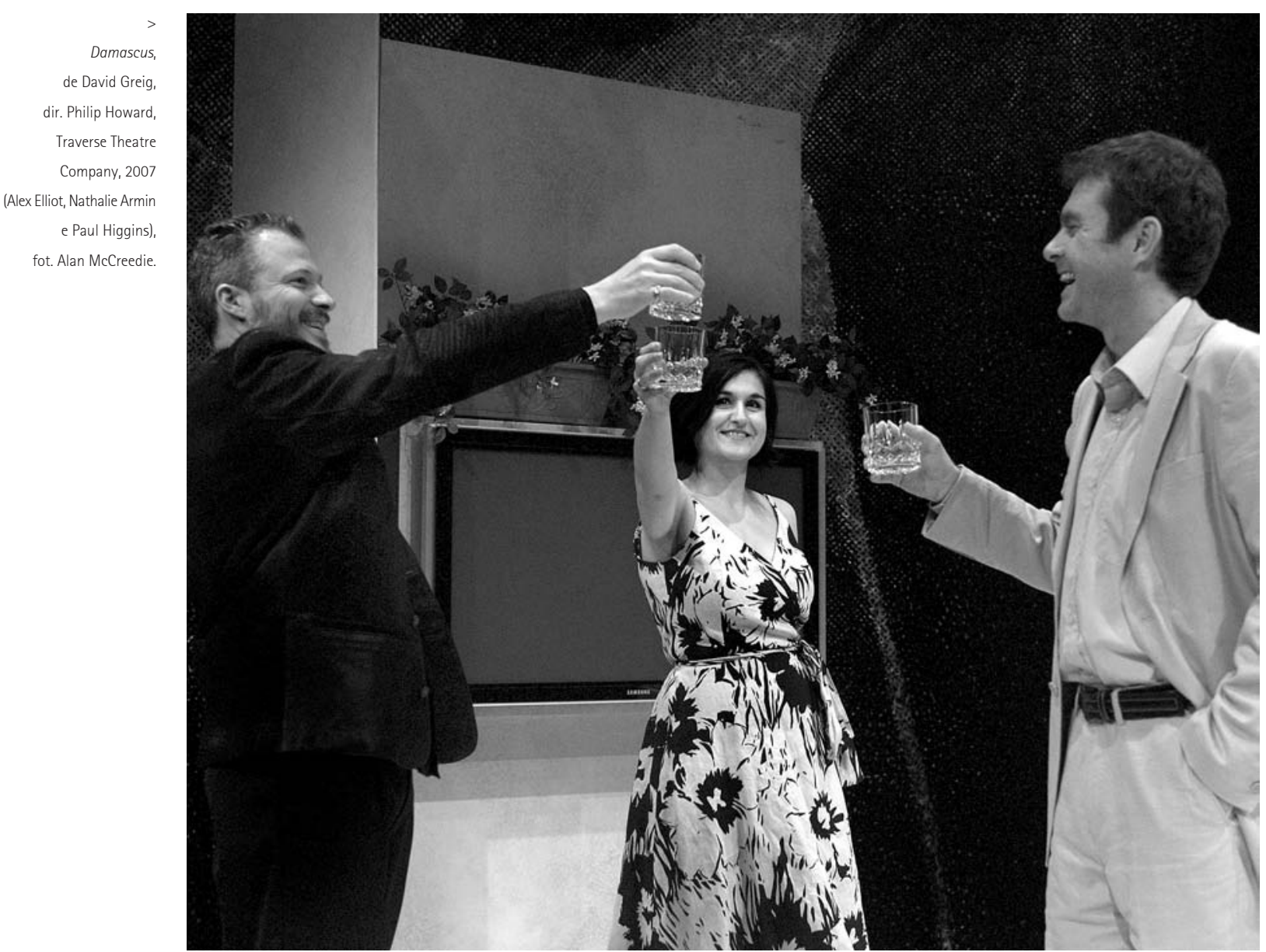

(Dolya Gavanski), a pianista ucraniana-cristã-ortodoxamarxista-psicóloga-transexual, vai instalando e

comentando a acção como se de um coro se tratasse.

Paul tem os sentidos alterados pois está fora do seu mundo: a metafórica ausência de cheiro com que a personagem chega a Damasco é sintomática do que já Tim Crouch evidenciava em England: o que somos depende de onde olhamos - transplantados para fora do nosso ambiente não passamos de um desconfortável corpo estranho.

Há demasiadas coisas que agrilhoam esta personagem ao seu local: o sotaque, a classe social, o whisky. Contudo, o embate de culturas é atenuado pois o espaço onde toda a acção se desenrola - um hall de hotel - é uma espécie de terra-de-ninguém: nem ocidente nem oriente. A única ligação ao mundo e à actualidade é uma televisão sempre ligada, mostrando imagens de um Médio Oriente em permanentes convulsões. Ainda assim, para Paul, centrado no seu olhar, os relatos de guerra iminente são só um estorvo que o impedem de voltar à Escócia e, em último caso, um pretexto para iniciar uma conversa fingindo interesse genuino.

Philip Howard dirige o espectáculo para a Traverse Theatre Company, local de excelência da nova dramaturgia escocesa, com uma linguagem cénica depurada, atenta ao ritmo do texto e instalando o foco na contracena. 0 cenário de Anthony Macllwaine sinaliza eficazmente 0 kitsch de um anónimo hotel, ainda que fique a meio caminho entre a construção de uma metáfora e a implementação de uma cena mais verista. Os únicos momentos que contrariam a lógica realista do espectáculo são os apartes (mais ou menos delirantes, mais ou menos líricos) da pianista. De resto, o registo é convencional e coloquial, tudo canonicamente arranjado: o herói agitado, o trio amoroso, o coro e o criado.

Contudo, é precisamente através desta última personagem que Damascus ganha um inusitado interesse. Zacharia, bufão e trapalhão, inconsequente ao ponto de aspirar que a sua boçal biografia possa ser motivo de um filme em Hollywood (ou, em última análise, de um qualquer canal televisivo escocês), enquanto personagem nunca aspira a superar a sua condição de criado. Todavia, com o seu gesto suicida final altera toda a estrutura interna do espectáculo colocando-se na posição de herói e protagonista. Damascus torna-se então não a história do vendedor de manuais de língua inglesa para estrangeiros, que de início não consegue sair da Síria e depois já não quer sair, para passar a ser a história do rapaz que só pensava em sair e rumar ao ocidente - Damascus passa a ser a história do rapaz que precisava de um transplante de pais.

Partindo de dois topónimos, England e Damascus, Crouch e Greig falam da constituição das identidades culturais e de como o mundo hoje se articula e relaciona. A globalização, a crescente facilidade de mobilidade, a constante procura por melhores condições de vida levam a que cada vez mais alguém esteja como estrangeiro num qualquer lugar. Num tempo que o mundo tem tendência para ser descrito a preto e branco, sabe bem olhar para todas as matizes coloridas que estes espectáculos propõem. Enquanto esperamos por um tempo em que os olhares não tenham raizes tão profundas. 